\title{
DISJUNÇÕES DOS PROCESSOS DE PATRIMONIALIZAÇÃO: identidades negras em territórios etnográficos
}

\author{
Luana Carla Martins Campos Akinruli ${ }^{1}$ \\ Samuel Ayobami Akinruli ${ }^{2}$
}

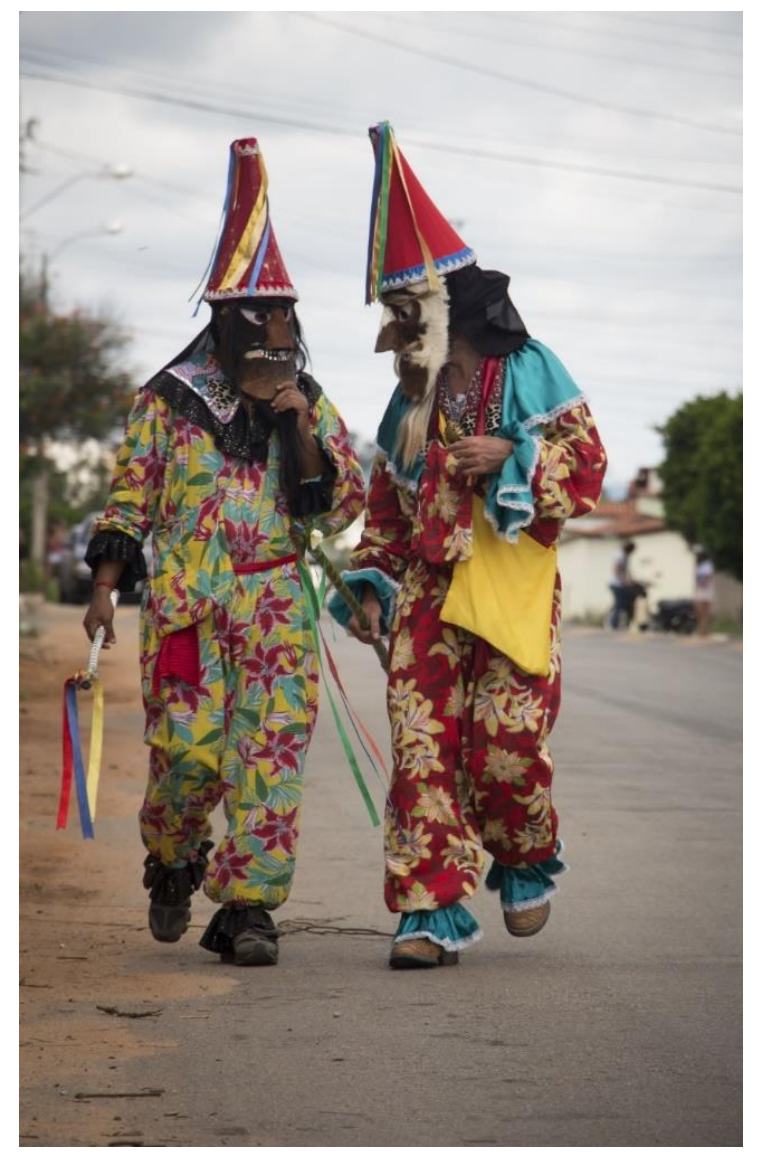

Palhaços da Folia de Reis.

São Gonçalo do Pará / Minas Gerais, 2016.

\footnotetext{
${ }^{1}$ Co-fundadora do Instituto de Inovação Social e Diversidade Cultural (INSOD) e coordenadora de projetos da mesma instituição. É doutoranda em Antropologia na Linha de Pesquisa Arqueologia do Mundo Moderno e Contemporâneo (UFMG), mestra em História pela Linha História Social da Cultura (UFMG) e licenciada em História (UFMG), com formação complementar em Antropologia e Arqueologia (UFMG). Atua em pesquisas versando sobre o patrimônio cultural, tendo realizado diversas consultorias e assessorias técnicas nos campos do patrimônio material e imaterial.

${ }^{2}$ Doutorando do Programa de Pós-Graduação em Ciência da Informação (UFMG/2018) pela linha de pesquisa Memória Social, Patrimônio e Produção do Conhecimento (PPGCI/UFMG). Possui mestrado em Inovação Tecnológica e Propriedade Intelectual pela Universidade Federal de Minas Gerais (UFMG/2014); especialização em Análise e Modelagem de Sistemas Ambientais / Geoprocessamento (UFMG/2017); bacharelado em Ciências Econômicas pela Lagos State University (Nigéria/2006), diploma reconhecido/revalidado pela Universidade Federal de Minas Gerais (UFMG/2015). É co-fundador do Instituto de Inovação Social e Diversidade Cultural (INSOD) com sede em Belo Horizonte/MG/Brasil, instituição no qual é presidente e gestor de inovação, sendo também filiado ao Conselho Regional de Economia (CORECON-MG).
} 


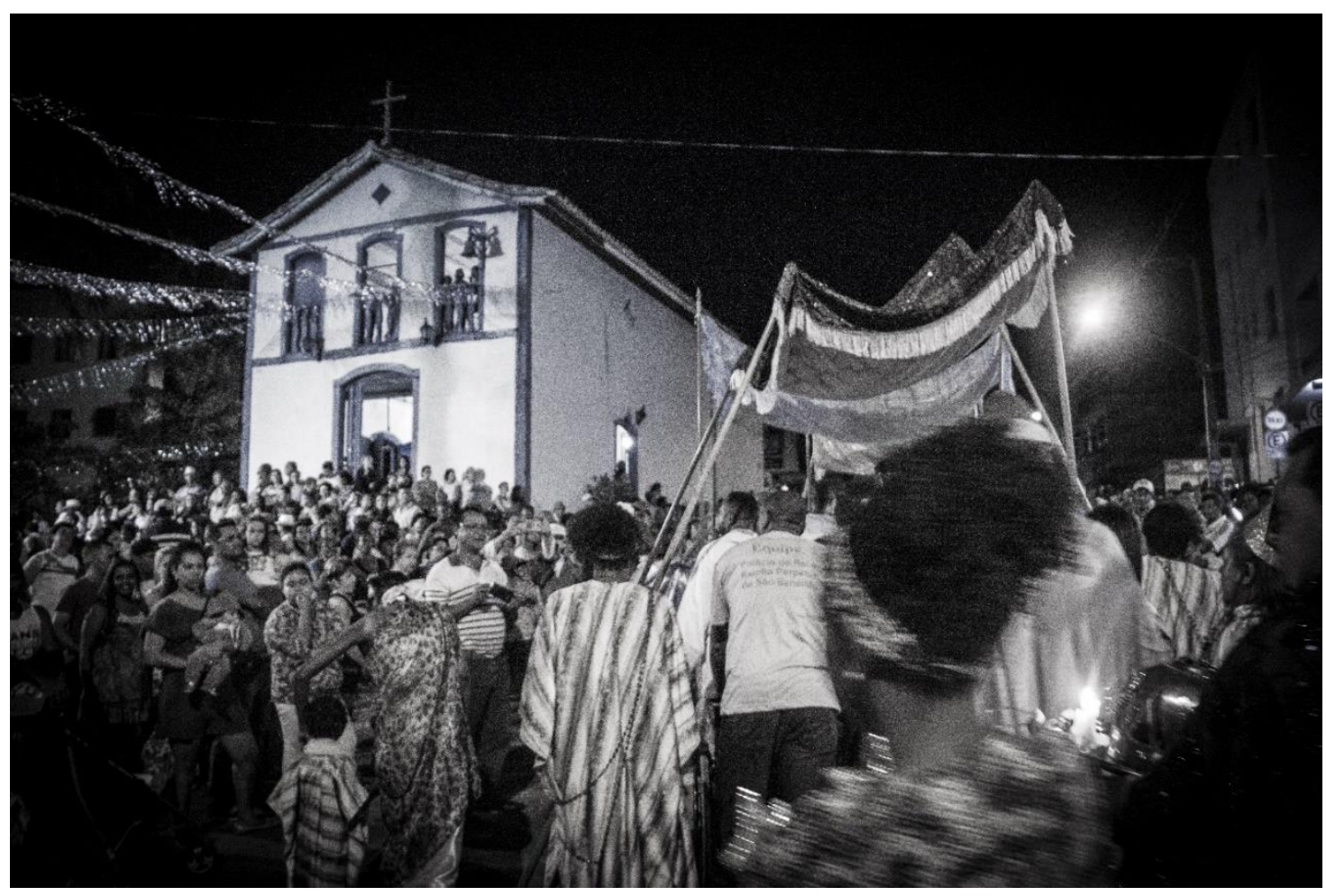

Reinado de Nossa Senhora do Rosário.

Carmo do Cajuru / Minas Gerais, 2016.

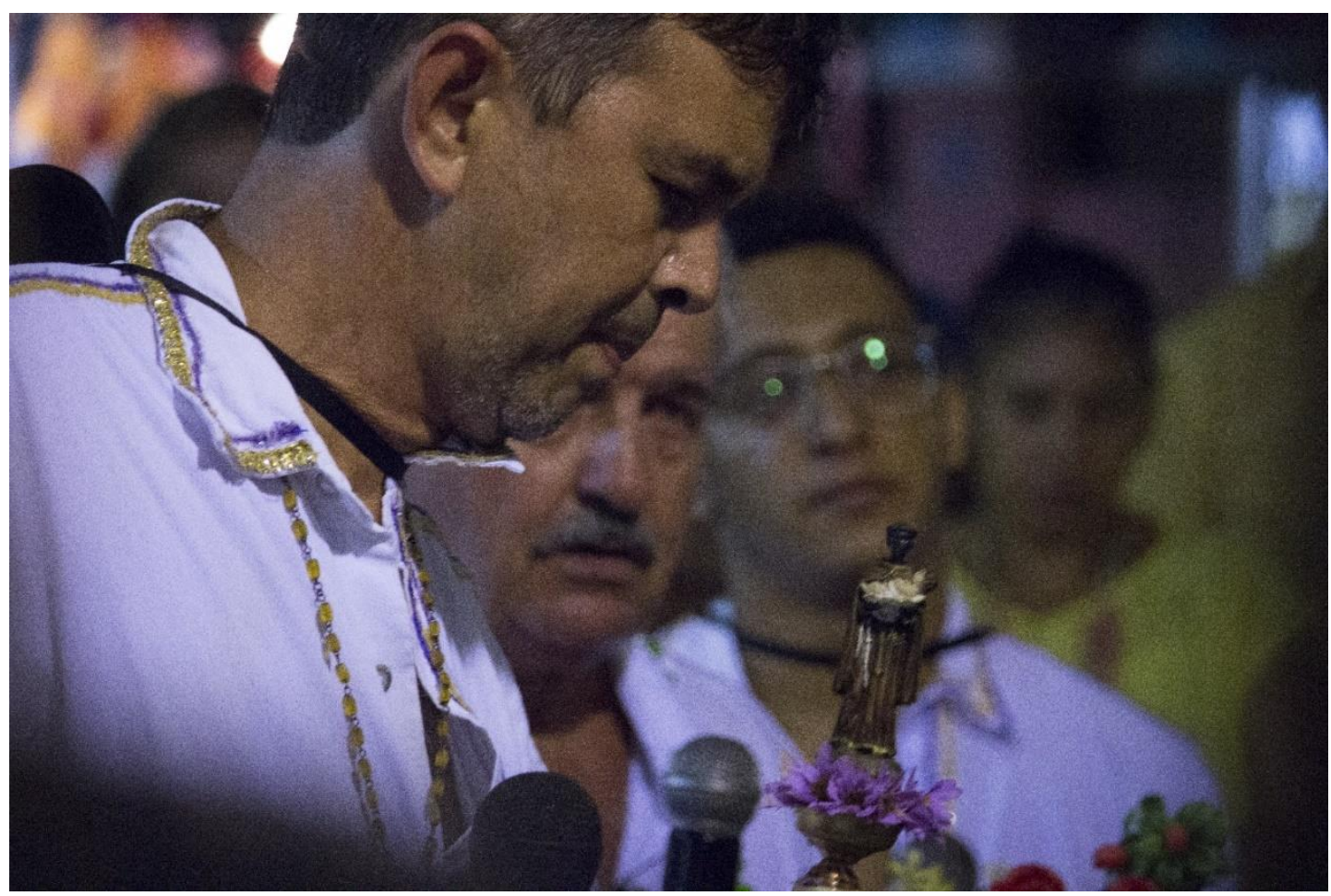

Terno de Moçambique Estrela do Oriente na Festa de $129^{\mathrm{a}}$ Festa da Congada. Pratápolis / Minas Gerais, 2016. 


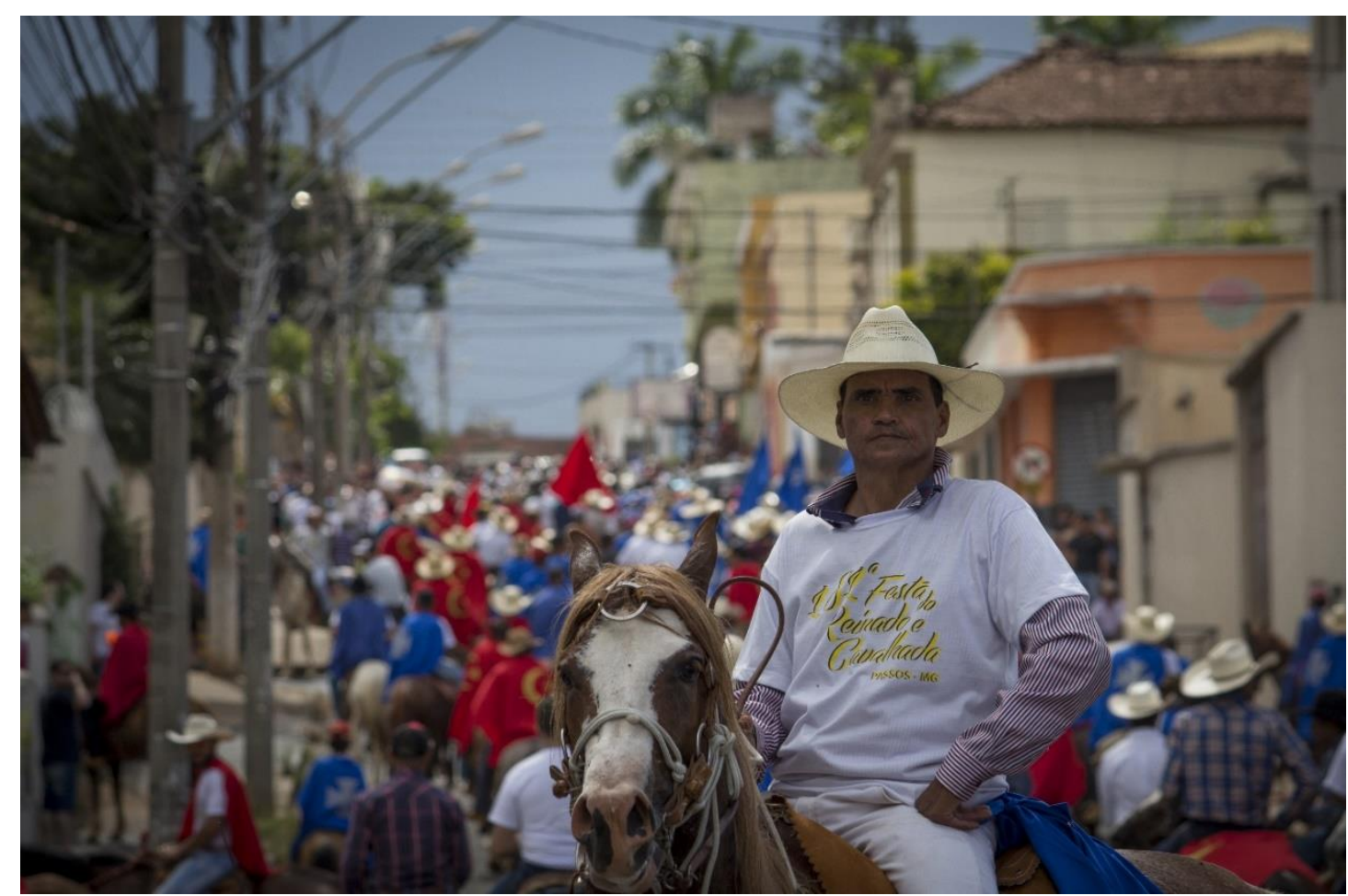

$181^{a}$ Festa do Reinado e Cavalhada.

Passos / Minas Gerais, 2016.

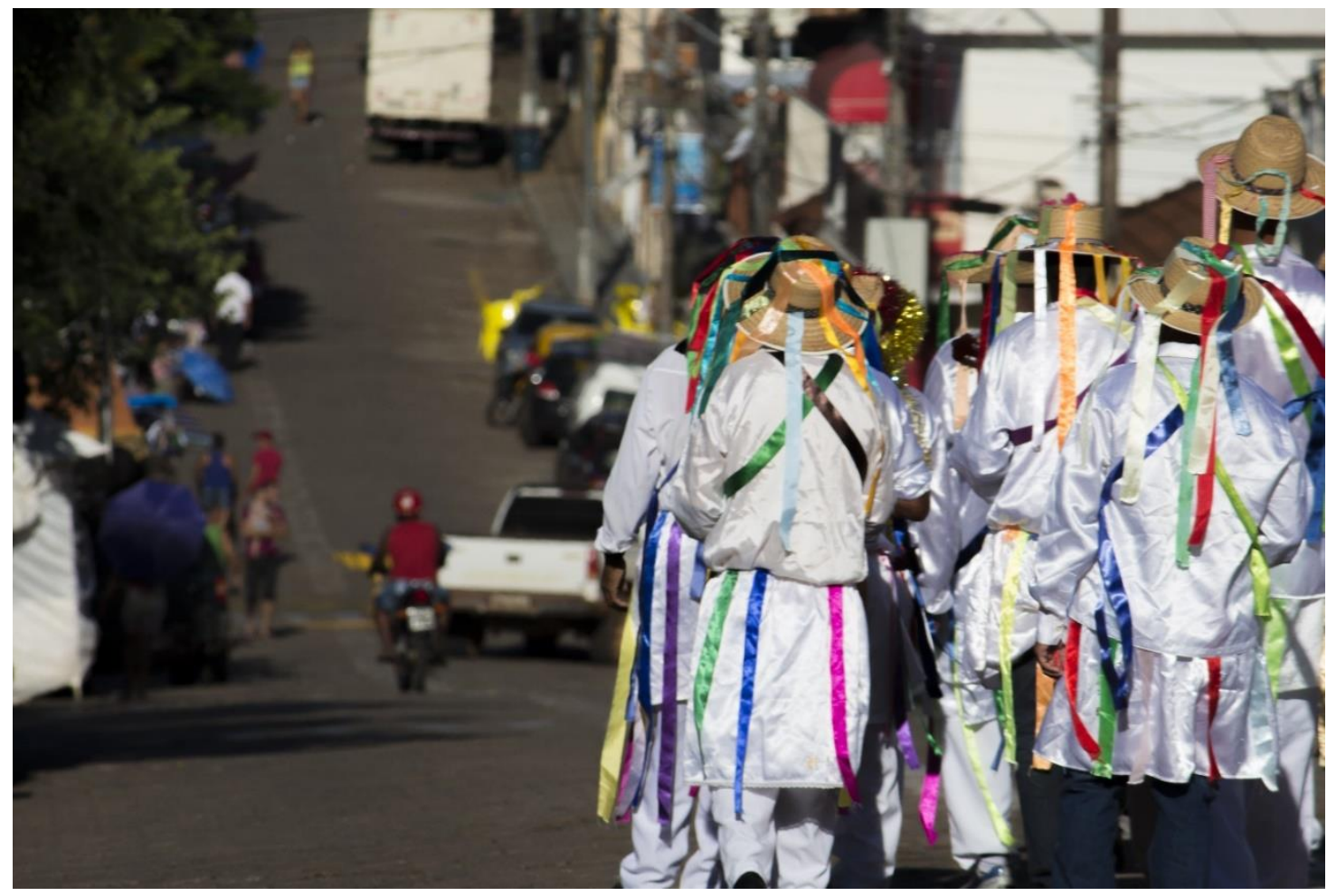

Terno de Moçambique São Benedito na $69^{\mathrm{a}}$ Congada Natalina. Itaú de Minas / M inas Gerais, 2016. 


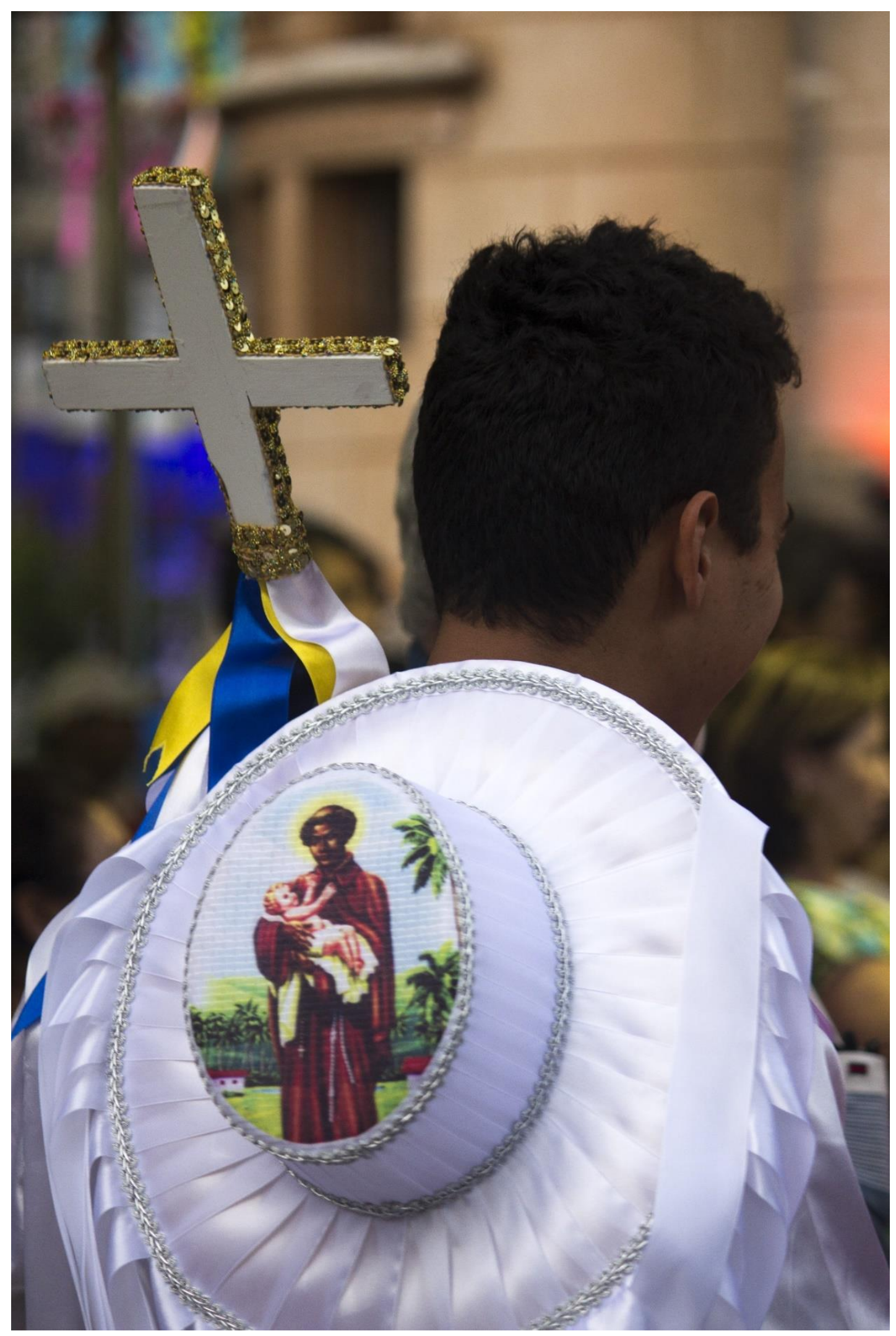

Festa de Congo e Moçambique.

São Sebastião do Paraíso / Minas Gerais, 2016.

INTRATEXTOS, Rio de Janeiro, vol. 9, n.1, 2018, p. 196-204. ISSN 2176-6789. DOI: 


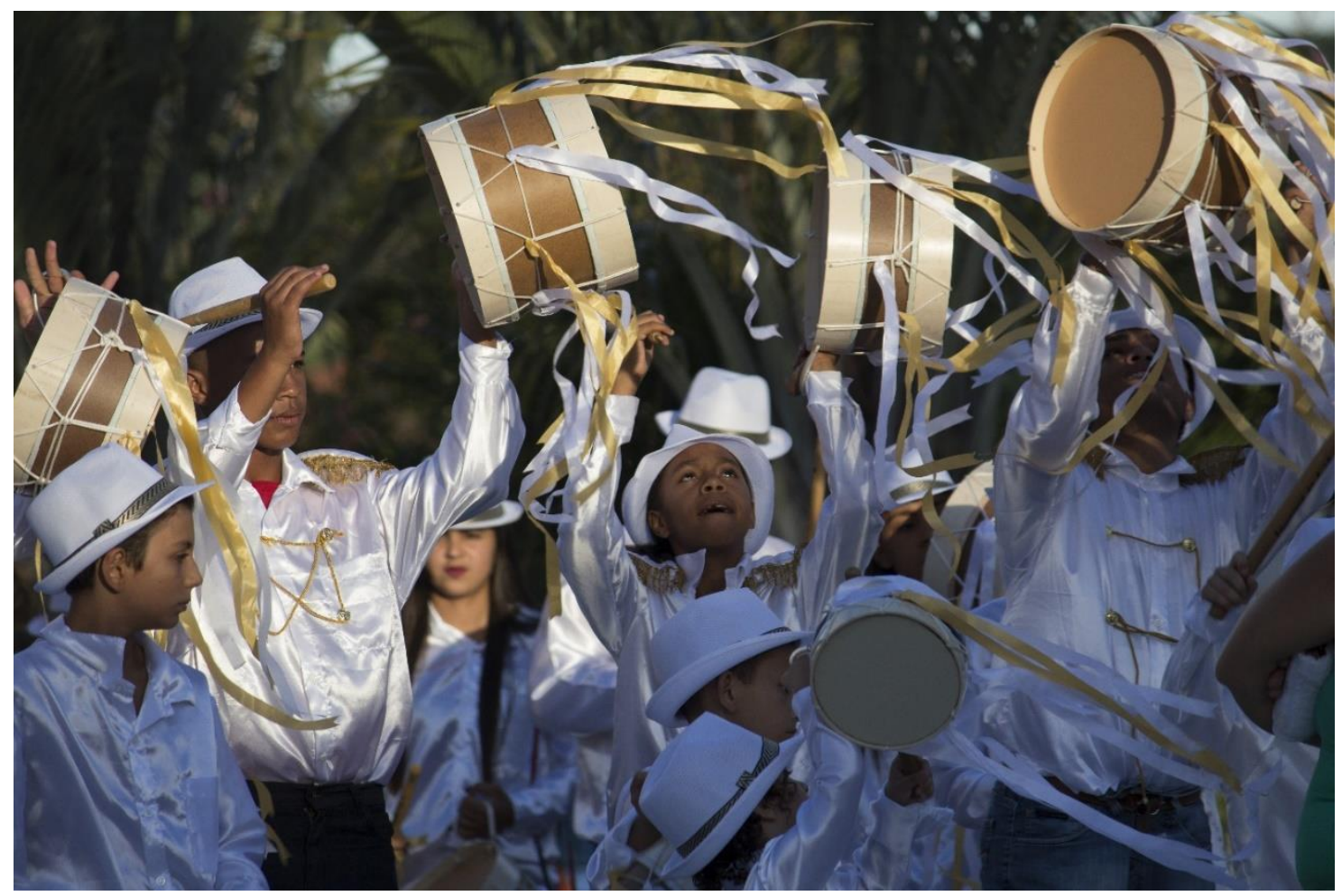

Terno de Congo do Menino Jesus na Festa de $129^{a}$ Festa da Congada. Pratápolis / Minas Gerais, 2016.

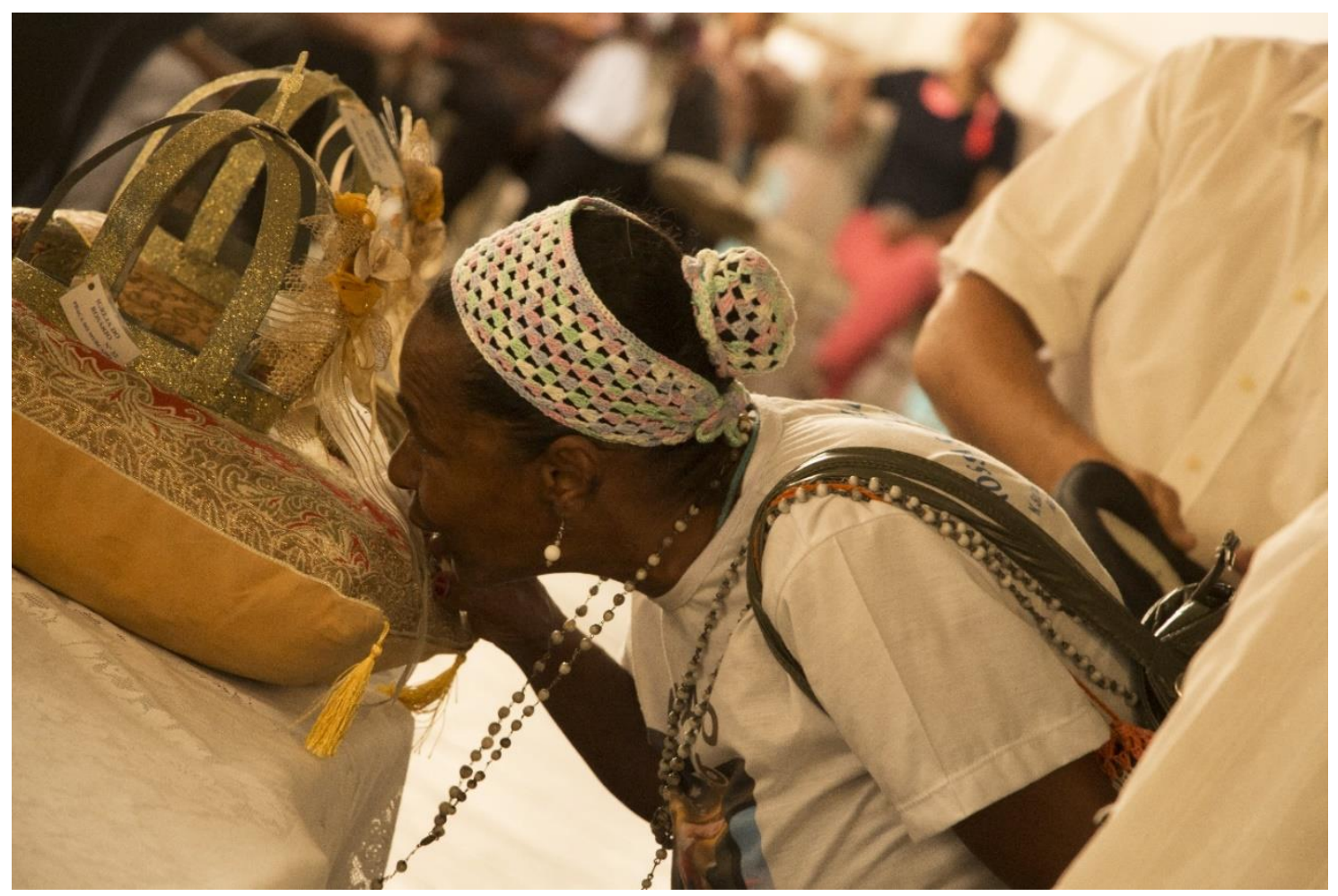

Reinado da Irmandade da Praça do Mercado.

Divinópolis / Minas Gerais, 2016.

INTRATEXTOS, Rio de Janeiro, vol. 9, n.1, 2018, p. 196-204. ISSN 2176-6789. DOI: 


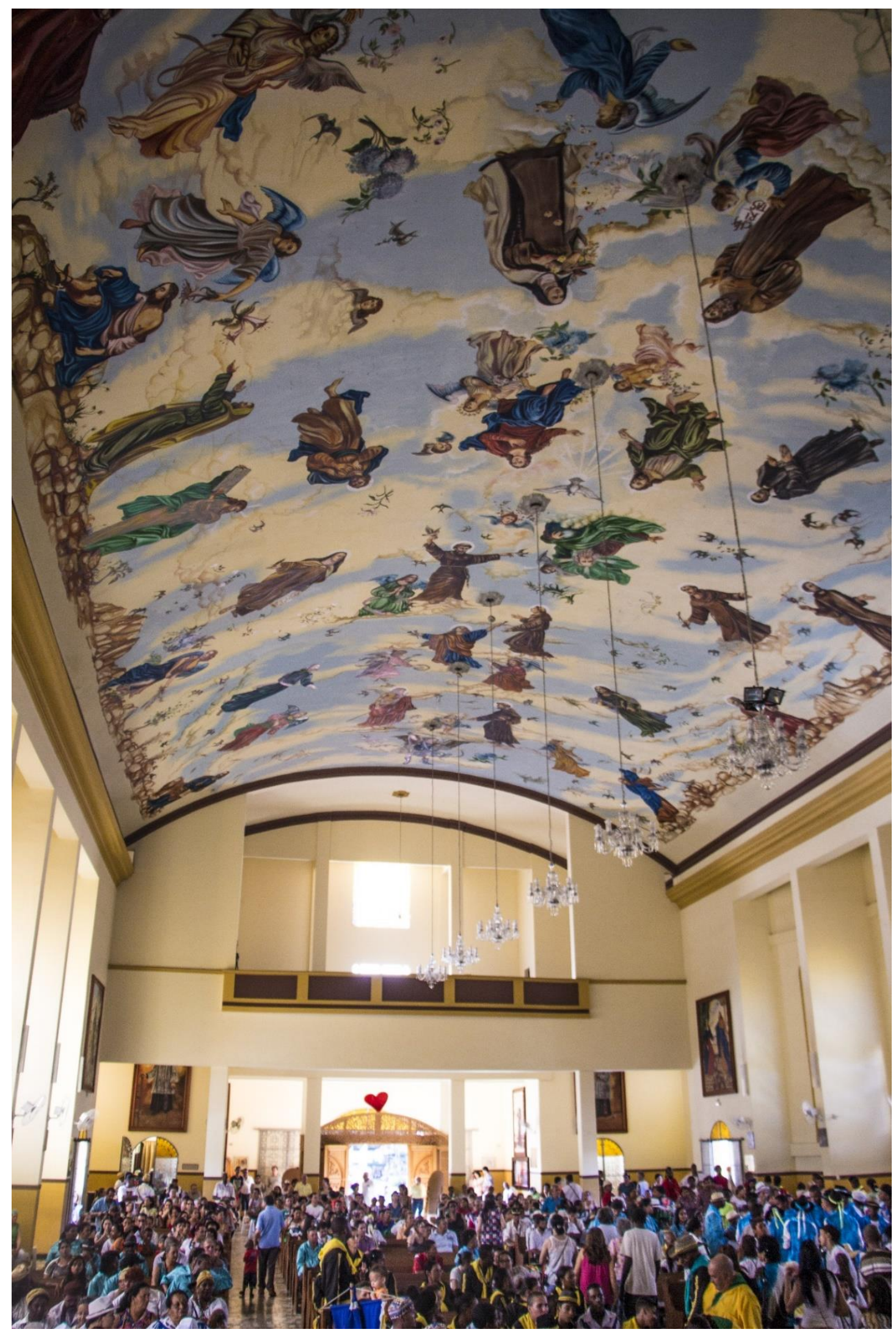

Missa Conga durante o Reinado da Irmandade da Praça do Mercado. Divinópolis / Minas Gerais, 2016. 


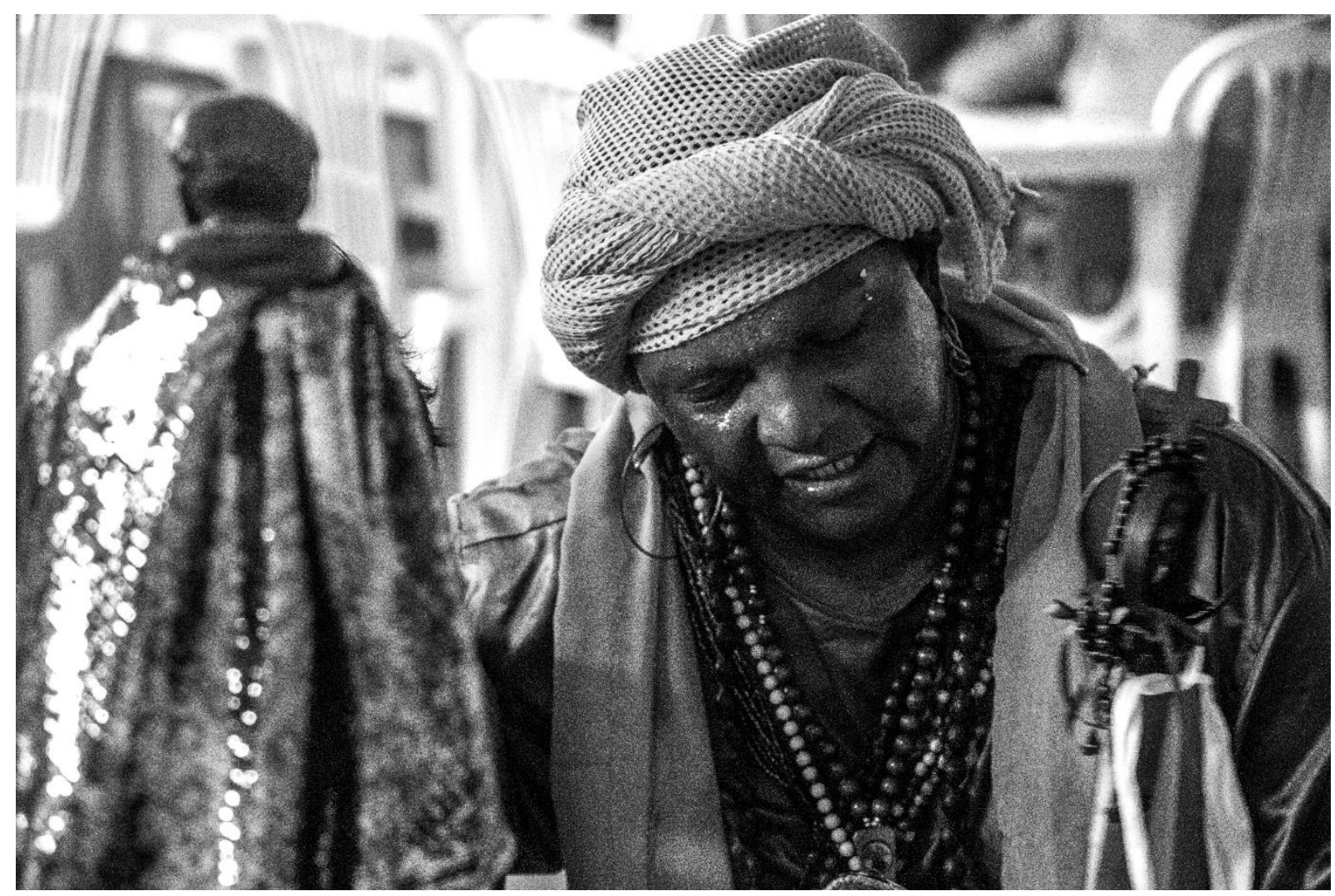

Festa do Reinado do Bairro Niterói.

Divinópolis / Minas Gerais, 2016.

Sete foram as cidades que percorremos, dispersas em uma região geográfica entre o sul, sudoeste e centro-oeste de Minas Gerais para a realização do Relatório de Avaliação de impacto ao Patrimônio Imaterial (RAIPI) para compor estudos técnicos para o Instituto do Patrimônio Histórico e Artístico Nacional (IPHAN) ao longo dos anos de 2016 e 2017. Espaço que foi se tornando lugar e, que na medida em que nos aproximamos, o zoom revelou um território vasto, imenso, extenso de identidades negras, múltiplas, controversas, fortes, resistentes, em construção. Das margens, a visão periférica sobressaiu ao olhar e se tornou o centro da narrativa, mostrando as disjunções dos procedimentos de patrimonialização dos quais a sociedade contemporânea se encerra. E que nós estamos imersos, obcecados.

A etnografia marcou o tempo do encontro, mas que já se fazia presente em nós anteriormente, na ancestralidade do contexto de diáspora. No encontro, deu-se a quebra da cumplicidade existente na consagração de uma determinada hegemonia do (re)conhecimento do patrimônio cultural - um específico savoir-faire que também promove violências epistêmicas e a deliberada invocação do patrimônio cultural. Ali não cabia mais uma postura 
colonizadora de lhes mostrar o que era da sua alma, o que era sua joia rara, a excepcionalidade, a monumentalidade do que era seu.

São muito variadas as possibilidades e formas de se invisibilizar, e a violência epistêmica, segundo Spivak (2010), constitui-se uma forma de se exercer o poder simbólico. Spivak argumenta que o subalterno não pode falar e, quando tenta fazê-lo, não encontra meios para se fazer ouvir. São tortuosos, complexos, incompreensíveis, obscuros, obtusos os procedimentos existentes nos estudos e pesquisas dedicados à identificação, documentação e salvaguarda do que se chama patrimônio cultural.

As edições, os esmaecimentos, os desfoques, os apagamentos, mostram-se de forma concreta em registros não somente da experiência, mas nas representações daquilo que se pesquisa. Há ângulos de visão distorcidos, e tratam-se de jogos de escalas nas quais coletividades "minúsculas" onde vivem pessoas "consideradas minúsculas" se chocam com políticas culturais municipais, estaduais ou federais de grande magnitude, colossais. Mas a mudança paradigmática do olhar logo se manifesta no trabalho de campo.

A experiência etnográfica trouxe confrontações, tensões e ressignificações dos sujeitos, de suas histórias, de suas memórias, de suas territorialidades, de suas múltiplas temporalidades. Agentes e agências envolvidos com os procedimentos de patrimonialização dos saberes considerados tradicionais promovem o processo de disputas de memórias e do lastro de pertencimento identitário, o agenciamento de espaços da cultura negra na cidade, o acionamento de mecanismos de potencial discursivo sobre as mudanças e permanências da cultura.

As formas de apropriação cultural e os revérberos no patrimônio cultural local em reflexões dialógicas entre o material e o imaterial da cultura não são tão translúcidas nas políticas públicas culturais relacionadas às tradições afro-brasileiras, que tendem a desqualificar a voz do outro e marginalizá-la, restringi-la a determinados tempos e espaços do calendário da urbe. Como criamos as ficções sobre os mundos dos outros e os nativos não podem se expressar por si mesmos por meio de categorias, conceitos e métodos próprios? Como não recorrer aos distanciamentos e exotizações sobre o outro que é também parte de nós?

Estas são reflexões que se posicionam não somente sobre os temas, enfoques e modos de descrever os objetos de estudo, mas sobre a forma da construção da própria narrativa, os agentes e agências envolvidos, a pretensa separação entre teoria e prática, bem como sobre os momentos da pesquisa de campo e da escrita. Para isso, são postos em análise a plataforma da 
experiência e do vivido como pontos fundamentais para promover um convite ao pensamento sobre a performance do pesquisado e do pesquisador em um contexto de alteridade.

O olhar etnográfico, registrado em instantes de manifestações transcorridas nas ruas, trazem luz o protagonismo da coletividade que tem consciência do seu lugar na sociedade, nas lutas cotidianas para poder se manifestar, permanecer, sobreviver, viver, ser. Entre Folias e Cavalhadas, os Reinados de Divinópolis, Carmo do Cajuru e São Gonçalo do Pará, e as Congadas e Moçambiques de São Sebastião do Paraíso, Pratápolis, Itaú de Minas e Passos; tornam híbridas expressões de catolicismo popular e de religiosidades negras, que se agregam pela força da fé em performances rituais.

Nos diversos modelos de etnografia possíveis, como as categorias nativas passam a dialogar, portanto, no duplo objetividade/subjetividade, haja vista que para além de simples dados etnográficos, tratam-se de conceitos e teorias compreendidas nos próprios termos dos outros? Cunha-se, nesta seara de falar com outro, não somente sobre o outro, a ponte entre a teoria antropológica e seus campos conexos, tendo a etnografia e o patrimônio cultural campos profícuos. O deslocamento do eixo promove a busca por outro balanço entre aquilo que é relevante e estruturante para o grupo etnografado. A polifonia passa a ser para além de uma experiência, é a gênese, o modelo de narrativa, o paradigma de construção do conhecimento.

\section{Referências Bibliográficas}

SPIVAK, Gayatri C. Pode o Subalterno Falar? Belo Horizonte: Editora UFMG, 2010.

Recebido em: Maio de 2018

Aprovado em: Julho de 2018 